\title{
L'ús de textos científics a les classes de física i química
}

\author{
Elena Seba Font \\ IES La Llauna, Badalona \\ mseba@xtec.cat
}

La finalitat d'aquest article és donar a conèixer el treball dut a terme durant una llicència d'estudis que va sorgir des de la convicció que la comprensió de lectures científiques és una habilitat necessària per a una persona amb una educació bàsica i que no es treballa a l'aula o no s'hi dedica prou temps. S'han seleccionat 152 textos científics classificats per temes, tipus $i$ nivell. S'ha estudiat àmpliament la teoria de l'argumentació de Perelman $i$ Olbrechts-Tyteca, el model d'Ogborn, les tipologies textuals, les estructures textuals segons Van Dijk, els mapes lògics de Thagard i la relació entre text i il-lustracions, per tal de dissenyar un marc teòric d'anàlisi de textos científics que proporcioni criteris per a seleccionar les lectures que es proposin dins de les matèries de Física i Química a l'ESO $i$ al Batxillerat..

Paraules clau: aprenentatge de les ciències, literatura científica, argumentació, Perelman, model d'Ogborn, estructures textuals, mapes lògics de Thagard, tipologia textual

\section{Introducció}

El professorat de ciències sovint constata les grans dificultats que presenten molts estudiants per expressar o comunicar idees o teories des d'un punt de vista científic, amb rigor, precisió de manera estructurada i coherent. Moltes vegades és difícil precisar si les dificultats provenen d'una mala comprensió dels conceptes, dels textos que han llegit o de no dominar el gènere lingüístic adequat.

La funció de qui ensenya ciències no es limita a l'explicació de conceptes pertanyents a l'àrea del coneixement científic, sinó que necessàriament comporta un ensenyament-aprenentatge de la llengua en el seu ús específic de comprensió i de producció; és a dir, com a eina de comunicació. I és evident que tota situació de comunicació requereix uns coneixements lingüístics i pragmàtics que s'aprenen mitjançant l'ús, l'observació i la reflexió.

També cal tenir present que una part important de les dificultats de l'aprenentatge de les ciències en general, i potser de manera especial de la química, prové de la dificultat d'atribuir sentit a conceptes que apareixen allunyats de la "realitat" que es viu i que els serveix de referència i els dóna suport. El treball amb lectures de divulgació científica ha de contribuir a reduir aquestes dificultats.

L'article que es presenta es basa en el treball dut a terme durant el període d'una llicència d'estudis i s'emmarca dins d'una línia de recerca actual, i en creixement, dins les facultats de Ciències de l'Educació d'arreu del món: la que s'interessa per la investigació de la comunicació a l'aula des de totes les perspectives possibles. La importància d'aquestes recerques es basa en que el fet comunicatiu és fonamental en el procés d'ensenyament-aprenentatge.

\section{Marc teòric per a l'anàlisi de textos científics}

A fi de poder elaborar criteris per a seleccionar les lectures que es proposin dins de les matèries de Física i Química a l'ESO i al Batxillerat, es presenta un marc teòric d'anàlisi de textos científics, estudiant-se més en profunditat el model d'Ogborn i la teoria de l'argumentació de Perelman. 


\section{S'ha estudiat:}

1) Tipologia textual, per poder classificar els diferents textos segons que siguin explicatius, argumentatius, descriptius, narratius o dialògics.

2) Estructures textuals segons Van Dijk. La macroestructura, superestructura i microestructura.

3) El model d'Ogborn, pensat inicialment pel discurs oral a les classes de ciències, però que es pot aplicar a textos de ciències. Segons el model d'Ogborn, per tal que una explicació científica tingui significat ha de respondre a una seqüència que es divideix en quatre etapes:

o creació de diferències

o construcció d'entitats

o transformació del coneixement

o donar significats a la matèria

4) La teoria de l'argumentació de Perelman i Olbrechts-Tyteca. Aquesta és una teoria retòricoargumentativa pensada per al llenguatge jurídic. Es va fer la hipòtesi que aquesta teoria també és aplicable a l'anàlisi de textos argumentatius. Es tracta de convèncer el lector a partir no només d'arguments, sinó de recursos retòrics i de donar presència a les dades presentades. Ensenyar als alumnes a trobar quines són les premisses i el tipus d'arguments d'un text contribueix a la seva comprensió i, a la vegada, els ensenya a argumentar. Després d'aplicar aquesta teoria a l'anàlisi de textos científics es va arribar a les conclusions següents:

o El model de Perelman s'ha mostrat útil per a poder analitzar els aspectes argumentatius- retòrics dels textos.

o És especialment rellevant l'anàlisi dels punts de partida o premisses de les argumentacions per saber si podrà donarse una comprensió significativa del text. La valoració de las premisses serà útil per saber si un text és adequat per un nivell específic d'estudiants.

- L'anàlisi argumentativa ens ajuda a veure si un text pot contribuir a la construcció de coneixement i/o si és adequat per aprendre a argumentar en base a coneixements que l'estudiant ja té.

o L'estudi d'aspectes retòrics dels textos, analitzats amb el model de Perelman es veu útil per poder apreciar la capacitat persuasiva del text i ens donarà orientació pel seu ús didàctic.

5) Els mapes lògics de Thagard, que pretenen analitzar les relacions que hi ha entre els diferents conceptes que apareixen en un text i saber de quina naturalesa són.

6) Relació entre text i il.lustracions segons Jiménez i Kress i Van Leeuwen:

o connotativa

o denotativa

0 sinòptica

\section{Recopilació de textos}

El resultat d'aquesta recerca ha conduït a l'obtenció dels materials següents:

- Un conjunt de 152 lectures (la majoria d'elles adaptades i traduïdes al català) aplicables a l'ensenyament de la Física i la Química a l'ESO i el Batxillerat que es poden emprar per motivar, introduir, completar o consolidar l'estudi d'algun tema del currículum. Els temes amb els quals estan relacionades aquestes lectures són els que s'indiquen a continuació:

o Canvis d'estat

o Calor i temperatura

o Científics

o Cinemàtica

o Dinàmica

o Dissolucions

o Electricitat

o Electromagnetisme

o Elements químics

o El mètode científic

o Energia

- Enllaç químic

o Espectres

- Estats de la matèria

- Física nuclear

o Gasos

o Materials

o Mol

- Nanotecnologia

o Ones electromagnètiques

o Òptica

o Osmosi

o Polímers

- Radioactivitat

o Reacció química 
o Reaccions redox

o Tècniques de purificació

o Teoria atòmica

- Teoria de la relativitat

o Unitats. Xifres

o Varis

La totalitat d'aquestes lectures es pot trobar com a annexos a l'adreça

http://phobos.xtec.es/sgfprp/resum.php?codi=970

- Un conjunt de lectures seleccionades per a la seva anàlisi.

- Un marc teòric d'anàlisi de textos científics a fi de poder elaborar criteris per seleccionar les lectures que es proposin dins de les matèries de Física i Química a l'ESO i al Batxillerat.

- L'anàlisi de les lectures seleccionades des de les perspectives esmentades al marc teòric (tipologia textual, estructures textuals segons Van Dijk, el model d'Ogborn, la teoria de l'argumentació de Perelman i Olbrechts-Tyteca,els mapes lògics de Thagard i relació entre text i il-lustracions segons Jiménez i Kress i Van Leeuwen)

- Base teòrica que serveix de marc referencial a l'hora de proposar activitats per després de la lectura.

- Models d'activitats per després de la lectura i qüestionaris aplicats a les lectures seleccionades

- Base de dades on s'hi pot trobar la informació següent:

o Índex dels temes tractats i enllaç

o Títol de les lectures classificades per temes i enllaç al text sencer.

o Tipus de lectura: iniciació, motivació, consolidació, ampliació...

- Nivell al qual es pot proposar

- Paraules clau, apartat "Altres documents" de l'adreça

http://phobos.xtec.es/sgfprp/resum.php?codi=970

\section{Exemples}

\section{El Mètode Científic}

\begin{tabular}{|l|l|l|l|}
\hline Títol & Tipus & Nivell & Paraules clau \\
\hline "Serendipi... què ? " & $\begin{array}{l}\text { Iniciació/ } \\
\text { Motivació }\end{array}$ & $\begin{array}{l}\text { 4t ESO/ } \\
\text { 1r Batxillerat }\end{array}$ & $\begin{array}{l}\text { Observació /sagacitat / descobriment } \\
\text { científic / serendipitat / Arquimedes / } \\
\text { Galvani / Volta }\end{array}$ \\
\hline "Tot el que és real és pensable" & Ampliació & Batxillerat & Hipòtesi / tesi / realitat / termodinàmica \\
\hline "El fluor, un assassí de químics" & Motivació & Batxillerat & $\begin{array}{l}\text { Gravat del vidre/ Scheele/ Davy/ elec- } \\
\text { tròlisi/ Moissan/ fitxa tècnica/ taules } \\
\text { cronològiques }\end{array}$ \\
\hline $\begin{array}{l}\text { "Record d'una vetllada memo- } \\
\text { rable al teatre de la Santa Creu" }\end{array}$ & Ampliació & Batxillerat & $\begin{array}{l}\text { Martí Franquès/ composició de l'aire/ } \\
\text { Scheele/ reacció química }\end{array}$ \\
\hline
\end{tabular}

\section{Dinàmica}

\begin{tabular}{|l|l|l|l|}
\hline Títol & Tipus & Nivell & Paraules clau \\
\hline $\begin{array}{l}\text { "Com reduir la mida d'un } \\
\text { col·lega i sortir airós de l'intent" }\end{array}$ & $\begin{array}{l}\text { Motivació/ } \\
\text { Consolidació }\end{array}$ & Batxillerat & $\begin{array}{l}\text { Conservació de la quantitat de movi- } \\
\text { ment/ força neta/ velocitat de retrocés }\end{array}$ \\
\hline "El gran geni d'Isaac Newton" & Motivació & $\begin{array}{l}\text { 3r,4t ESO / } \\
\text { Batxillerat }\end{array}$ & Llei de la gravitació universal \\
\hline
\end{tabular}




\begin{tabular}{|l|l|l|l|}
\hline $\begin{array}{l}\text { "El productes eterns: fets per du- } \\
\text { rar" }\end{array}$ & $\begin{array}{l}\text { Iniciació/ Mo- } \\
\text { tivació }\end{array}$ & 3r, 4t ESO & Força de fregament \\
\hline $\begin{array}{c}\text { "'Final fantasy, the spirit } \\
\text { within' o la castanya final..." }\end{array}$ & $\begin{array}{l}\text { Motivació/ } \\
\text { Ampliació }\end{array}$ & Batxillerat & $\begin{array}{l}\text { Fregament / energia cinètica / energia } \\
\text { tèrmica / velocitat límit }\end{array}$ \\
\hline $\begin{array}{l}\text { "Pot aixecar-se un mateix } \\
\text { estirant-se els cabells?" }\end{array}$ & $\begin{array}{l}\text { Iniciació/ Mo- } \\
\text { tivació }\end{array}$ & $\begin{array}{l}4 \mathrm{t} \text { ESO / } \\
\text { Batxillerat }\end{array}$ & $\begin{array}{l}\text { Forces internes / forces externes / força } \\
\text { de reacció }\end{array}$ \\
\hline $\begin{array}{l}\text { "En caiguda lliure...fins a les } \\
\text { antípodes" }\end{array}$ & $\begin{array}{l}\text { Motivació/ } \\
\text { Ampliació }\end{array}$ & Batxillerat & $\begin{array}{l}\text { Llei de la gravitació / massa / volum } \\
\text { d'una esfera / densitat / inèrcia / movi- } \\
\text { ment harmònic simple }\end{array}$ \\
\hline "Es pot evitar la gravetat?" & Ampliació & Batxillerat & $\begin{array}{l}\text { Ciència -ficció / galàxies / "cavorita" / } \\
\text { Einstein / teoria de la relativitat general }\end{array}$ \\
\hline
\end{tabular}

\section{Unitats. Xifres}

\begin{tabular}{|l|l|l|l|}
\hline Títol & Tipus & Nivell & Paraules clau \\
\hline $\begin{array}{l}\text { "Moltes pel-lícules fan gala d'un } \\
\text { anumerisme exagerat" }\end{array}$ & $\begin{array}{l}\text { Motivació / } \\
\text { Consolidació }\end{array}$ & $\begin{array}{l}4 \mathrm{t} \text { ESO / } \\
\text { 1r Batxillerat }\end{array}$ & $\begin{array}{l}\text { Anumerisme / any llum / nombre } \\
\text { d'estrelles / so / decibels / potències }\end{array}$ \\
\hline "Gegants i nans del firmament" & Ampliació & $\begin{array}{l}4 \mathrm{t} \text { ESO / } \\
\text { Batxillerat }\end{array}$ & $\begin{array}{l}\text { Magnituds estel.lars / magnitud absolu- } \\
\text { ta / grandària de les estrelles / evolució } \\
\text { estel-lar }\end{array}$ \\
\hline $\begin{array}{l}\text { "Celsius o Fahrenheit?" } \\
\text { mètric" }\end{array}$ & $\begin{array}{l}\text { Motivació / } \\
\text { Iniciació }\end{array}$ & $4 \mathrm{t}$ ESO & $\begin{array}{l}\text { Fahrenheit 451 / grau termomètric / es- } \\
\text { cala Fahrenheit / escala Celsius }\end{array}$ \\
\hline $\begin{array}{l}\text { "Físics vienesos aconsegueixen } \\
\text { mesurar l'instant de temps més } \\
\text { petit" }\end{array}$ & $\begin{array}{l}\text { Notícia / } \\
\text { Ampliació } \\
\text { Iniciació }\end{array}$ & $\begin{array}{l}\text { 4t ESO / } \\
\text { Batxillerat }\end{array}$ & $\begin{array}{l}\text { Attosegon / àtom / embolcall electrònic } \\
\text { polzada / les mides catalanes / peu / }\end{array}$ \\
\hline $\begin{array}{l}\text { "1000 atmosferes sota la punta } \\
\text { del dit" }\end{array}$ & Consolidació & $\begin{array}{l}4 \mathrm{t} \text { ESO / } \\
\text { 1r Batxillerat }\end{array}$ & Pressió / força / atmosfera \\
\hline $\begin{array}{l}\text { "Deu vegades més ràpid que el } \\
\text { so" }\end{array}$ & $\begin{array}{l}\text { Notícia / } \\
\text { Ampliació }\end{array}$ & $\begin{array}{l}4 \mathrm{t} \text { ESO / } \\
\text { Batxillerat }\end{array}$ & $\begin{array}{l}\text { Mach / avió hipersònic/ combustió su- } \\
\text { persònica }\end{array}$ \\
\hline $\begin{array}{l}\text { "Los especialistas proponen re- } \\
\text { definir el kg como fenómeno na- } \\
\text { tural" }\end{array}$ & $\begin{array}{l}\text { Notícia / } \\
\text { Ampliació }\end{array}$ & $\begin{array}{l}4 \mathrm{t} \text { ESO / } \\
\text { Batxillerat }\end{array}$ & $\begin{array}{l}\text { Metrologia / kg patró / metre / segon / } \\
\text { velocitat de la llum }\end{array}$ \\
\hline
\end{tabular}

\section{Bibliografia}

Kress, G.; van Leuven, T. (1996). Reading Images. The Grammar of Visual Design, London: Routledge.

Ogborn, J. (1997). Explaining Science in the classroom. Buckingham: Open University Press.
Perelmen, Ch. i Olbrechts-Tyteca (1989). Tratado de la argumentación. La Nueva Retórica, Madrid: Gredos.

Sanmartí, N. et al. (2002). Aprendre ciències tot aprenent a escriure ciència, Barcelona: Edicions 62. 
Thagard, P. (1992). Conceptual Revolutins. Princeton : Princeton University Press.

Thagard, P. "Conceptual Change" dins Encyclopedia of Cognitive Science, London: MacMillan, vol. 1, (2003) p. 666-670.

Van Dijk, T. A. La ciència del text. Un enfocament interdisciplinari. Barcelona: Ed. Paidós, (1983)
Aquest treball s'ha realitzat gràcies a una llicència d'estudis concedida pel Departament d'Educació de la Generalitat de Catalunya amb el títol "Selecció $i$ anàlisi de lectures científiques per a l'ensenyament secundari", sota la direcció de la Dra. Marina Castells, dins el grup de recerca GRIEC de la Universitat de Barcelona. 